\title{
Prognostic Value of Myocardial Scar In Ischemic And Non- Ischemic Cardiomyopathy Using Cardiac Magnetic Resonance Imaging
}

Reem Laymouna ( $\nabla$ reemlamona@gmail.com )

Alexandria University Faculty of Medicine https://orcid.org/0000-0002-5801-6588

Eman El-Sharkawy

Alexandria University Faculty of Medicine

Salah El-Tahan

Alexandria University Faculty of Medicine

Mohamed El-Fiky

Alexandria University Faculty of Medicine

\section{Research Article}

Keywords: Ischaemic cardiomyopathy, non-ischaemic cardiomyopathy, cardiac MRI, myocardial scar

Posted Date: July 12th, 2021

DOI: https://doi.org/10.21203/rs.3.rs-679631/v1

License: @ (1) This work is licensed under a Creative Commons Attribution 4.0 International License. Read Full License 


\section{Abstract}

Purpose is to evaluate the prognostic value of myocardial scar/fibrosis using cardiac magnetic resonance (CMR) in patients with ischaemic cardiomyopathy (ICM) and non-ischaemic cardiomyopathy (NICM).

Methods; 156 patients with either ICM or NICM underwent CMR with late gadolinium enhancement (LGE) sequences for assessment of left ventricular ejection fraction (EF), detection and quantification of any myocardial scar/fibrosis using three methods; a) manual, b) number of segments involved, c) percentage of scarred myocardium (segment based). Patients were followed up for at least 6 months for any clinical cardiac event.

Results: Males were 56\% (mean age 61 years), with minimal follow up (FU) of 6 months. Patients were divided into; group l; ICM (58\%) and group II; NICM (36\%). Clinical presentation was ranging from eventless (10\%), chest pain (18\%), heart failure (15\%), hospitalization $(35 \%)$, syncope $(1 \%)$, ventricular tachycardia $(<1 \%)$ and cardiac arrest $(<1 \%)$. The scar mass was more in size in group I $(17 \% \pm 15)$ than in group II $(8 \% \pm 13)$. Direct linear relationship was observed between scar size and event severity $(P$ value $<0.001)$.

Inverted relationship between LVEF and event severity in group I ( P value of $<0.001$ ) was detected, however, no significant correlation between LVEF and event severity in group II (P value 0.128 ).

Conclusion: Myocardial scar size is a strong predictor for the clinical outcome in both ICM and NICM. EF is less reliable to predict morbidity in cardiomyopathy patients. Segments dependent methods for quantification of myocardial scar is comparable to the manual LGE quantifications.

\section{Introduction}

Cardiac muscle is a unique muscle type to perform a specific function; conducting electrical activity to both ventricle simultaneously to contract and relax in a synchronized manner, pumping the blood to the whole body with a proper myocardial reserve to meet the varying physiological body situations. Therefore, evaluation of the myocardial muscle function using only ejection fraction (EF) would be inaccurate.

However, assessment of myocardium on the tissue level and how healthy it is, is expected to provide more precise data regarding the ability to conduct, contract and relax properly. Tissue characterization using cardiac magnetic resonance (CMR) provides more knowledge about the pathological processes occurring in different types of cardiomyopathy, hence, more prognostic information about each type of cardiomyopathy.

Gadolinium contrast has a large molecular size that allows it to distribute in the extra-cellular space without penetrating the intact myocardial cells under normal conditions. However, in certain pathologic circumstances, either the extracellular space may increase (e.g. in some non-ischaemic cardiomyopathy) or the myocardial cell membrane may be disrupted (e.g. in ischaemic cardiomyopathy), leading to an increase in the amount of gadolinium distribution leading to gadolinium enhancement $[1,2]$.

Different types of cardiomyopathies exhibit different patterns of late enhancement, which opens up entirely new possibilities in the differential diagnosis in patients with ventricular dysfunction. LGE is based on differences in extracellular space in different areas of myocardium, therefore it is more useful when the fibrosis is regional (e.g. myocarditis, myocardial infarction scar, sarcoidosis and hypertrophic cardiomyopathy).

Currently, there is no uniform approved way to quantify the myocardial scar size in cardiac MRI late gadolinium enhancement sequences. Several methods have been used; e.g. number of segments with scar, manual planimetry of the enhanced myocardium, and automatic quantification using signal thresholding techniques to determine scar borders. For the latter approach, most often the fullwidth at half maximum (FWHM) technique and 2-standard deviation (SD) technique was used, as described originally by Kim et al.[3] for myocardial infarction.

Our study main aim is evaluate the prognostic value of myocardial scar using cardiac magnetic resonance on the clinical outcome in patients with ischemic and non-ischemic cardiomyopathy and compare it to the prognostic value of the LV ejection fraction in the same study population.

\section{Methods}


This study included 156 patients who were diagnosed to have cardiomyopathy (both ischaemic and non-ischaemic) using cardiac MRI 1.5 tesla.

CMR was performed using a 1.5-T system. Sequences were ECG-triggered and performed in breath hold technique using a body array coil. Myocardial function was assessed with cine steady state free precession (SSFP) pulse sequence that were acquired in stack of short axis (SA) slices covering whole LV with eight-ten contiguous sections. LGE was acquired 10 minutes after I.V. gadolinium contrast $(0.2 \mathrm{mmol} / \mathrm{kg})$ by using a gradient spoiled turbo fast low-angle shot sequence with phase-sensitive inversion recovery technique in the four-chamber, two-chamber and a series of LV short axes (section thickness $6 \mathrm{~mm}$ ).

The cardiac MRI study analysis included a) ventricular function assessment (EF), though volumes measurements in the short axis (SA) cine images. b) detection of any myocardial scar or fibrosis using; short axis, 2,3 and 4 chamber late gadolinium enhancement images. c) quantification of myocardial scar/fibrosis using 3 methods: 1 . Manual quantification of the LGE mass in each slice of the SA late gadolinium sequence. 2. Number of segments involved in the scar tissue (segments involving LGE). 3. Percentage of the scarred myocardium (summation of the $\%$ of the scarred myocardium in each segment in relation to the total LV mass).

All the 156 were followed up for at least 6 months for any clinical cardiac events. These events were scaled according to severity from 1 (less severe) to 7 (most severe); ranging from mild chest pain (non-acute coronary syndrome), mild dyspnoea (NYHA I-II) and including hospital admission due to decompensated heart failure and up to syncope, documented ventricular arrhythmia and sudden cardiac arrest/death, respectively.

Statistical correlation between the amount of the scarred myocardium in both ischaemic and non-ischaemic cardiomyopathy patients and the severity of the clinical events during the period of the follow up was performed.

\section{Statistical analysis of the data}

Data were fed to the computer and analyzed using IBM SPSS software package version 20.0. (Armonk, NY: IBM Corp). The KolmogorovSmirnov was used to verify the normality of distribution of variables. Spearman coefficient was used to correlate between quantitative variables Significance of the obtained results was judged at the $5 \%$ level.

\section{Results}

One hundred fifty six patients were included in the study, 87 patients (56\%) were males and 69 patients (44\%) were females with a mean age of 61 years $+/-15$ (ranging from 20-87 years). The duration of the clinical follow up was variable with minimal of 6 months, mean of 10 months (from 6-40m).

Our patients are mainly divided into two groups; 89 (58\%) patients were diagnosed to have ischemic cardiomyopathy and 56 (36\%) patients to have non-ischemic cardiomyopathy.

The non-ischemic subgroup (65patients) involved a variety of different etiologies of cardiomyopathies; 41 patients were diagnosed to have dilated cardiomyopathy (DCM), 7 patients with Takotsubo cardiomyopathy, 5 patients with LV non-compaction, 4 patients with apical non-obstructive hypertrophic cardiomyopathy (HCM), 3 patients with amyloidosis, 2 patients with sarcoidosis, 2 patients with arrhythmogenic left ventricular dysplasia and one patient with endomyocardial fibrosis.

Of the 154 patients, 52 (34\%) have EF < 45\% (28 patients of group I, 24 patients in group II) and 102 (66\%) patients have EF $\geq 45 \%$ (61 patients of group I, 41 patients in group II).

All the 154 patients were followed up clinically for at least 6 months. The clinical presentation was ranging from eventless (no events) in 16 patients (6 of the ischemic group, 10 of the non-ischemic group), chest pain in 28 (18\%) patients (19 of group I, 9 of group II), heart failure in 23 (15\%) patients (12 of group I, 11 of group II), hospitalization in 54 (35\%) patients (35 of group I, 19 of group II), syncope in $14(1 \%)$ patients (6 of group I, 8 in group II), ventricular tachycardia $9(<1 \%)$ patients ( 5 of group I, 4 of group II) and cardiac arrest 10 (< $1 \%)$ patients (6 of group I, 4 of group II).

Our main concern in this study is to figure out if there is a relation between the scar size detected in the late gadolinium CMR and the severity of clinical presentation of the patient in the duration of the follow up. 
In our study, direct relationship between the absolute size of the myocardial scar in grams and event severity was observed $(P$ value $<$ $\left.0.001, r_{s} 0.464\right)$ as shown in table (1) and figure (1). When the two subgroups were compared, the scar mass was more in size in group I $(19.5 \mathrm{~g} \pm 18.9)$ than in group II $(11.3 \mathrm{~g} \pm 19.9)$ but still with linear relationship between scar size and event severity $(P$ value $<0.001)$ in both groups, (Fig. 1).

The size of the scar was also assessed by the total number of segment involved in the scar. Again, there was a significant direct relationship between the number of segments involved in this scar and event severity in both subgroups (group I; $\mathrm{P}$ value $<0.001, \mathrm{r}_{\mathrm{s}}$ 0.490 , group Il; $P$ value $\left.<0.001, r_{s} 0.536\right)$.

The 3rd method to evaluate the myocardial scar mass is through calculation of the percentage of myocardial scar to the total myocardial mass (by estimating the \% of scar tissue in each segment of the 17 myocardial segments separately, each myocardial segment represent $1 / 17$ of the total myocardial mass). The mean scar percentage was $17 \% \pm 15$ in ischemic patients and $8 \% \pm 13$ in the non-ischemic cardiomyopathy patients. There was also a direct relationship observed between the estimated percentage of scarred myocardium and event severity; (group I; $P$ value < 0.001, $r_{s} 0.468$, group Il; $P$ value < 0.001, $r_{s} 0.558$ ), (Fig. 2).

Regarding the LV systolic function assessed by the LV ejection fraction (EF), there was an inverse relationship between the ejection fraction and event severity in the ischemic group (group I) with P value of $0.013\left(r_{s}\right.$ of -0.263$)$ (Fig. 3). This was different from the results of the 2nd group where there was no significant correlation between the LV ejection fraction and the event severity $\left(P\right.$ value $0.128, r_{s}$ $0.180)$.

Table (1): Analysis of scar mass, actual no. of scar seg, \% of scar and EF in event groups

\begin{tabular}{|c|c|c|c|c|c|c|c|c|c|c|c|c|}
\hline \multirow[t]{3}{*}{ Event } & \multicolumn{3}{|c|}{ Scar Mass (gm) } & \multicolumn{3}{|c|}{ Actual no. of scar seg } & \multicolumn{3}{|c|}{$\%$ of scar } & \multicolumn{3}{|c|}{ LVEF (\%) } \\
\hline & Total* & $\begin{array}{l}\text { Group } \\
\left.\right|^{*}\end{array}$ & $\begin{array}{l}\text { Group } \\
\|^{*}\end{array}$ & Total* & $\begin{array}{l}\text { Group } \\
\left.\right|^{\star}\end{array}$ & $\begin{array}{l}\text { Group } \\
\|^{*}\end{array}$ & Total* & $\begin{array}{l}\text { Group } \\
\left.\right|^{*}\end{array}$ & $\begin{array}{l}\text { Group } \\
\|^{*}\end{array}$ & Total & Group|* & Groupll \\
\hline & $\begin{array}{l}\text { Mean } \\
\pm \text { SD }\end{array}$ & $\begin{array}{l}\text { Mean } \\
\pm \text { SD }\end{array}$ & $\begin{array}{l}\text { Mean } \\
\pm \text { SD }\end{array}$ & $\begin{array}{l}\text { Mean } \\
\pm \text { SD }\end{array}$ & $\begin{array}{l}\text { Mean } \\
\pm S D\end{array}$ & $\begin{array}{l}\text { Mean } \\
\pm \text { SD }\end{array}$ & $\begin{array}{l}\text { Mean } \\
\pm S D\end{array}$ & $\begin{array}{l}\text { Mean } \\
\pm S D\end{array}$ & $\begin{array}{l}\text { Mean } \\
\pm S D\end{array}$ & $\begin{array}{l}\text { Mean } \\
\pm \text { SD }\end{array}$ & $\begin{array}{l}\text { Mean } \\
\pm \text { SD }\end{array}$ & $\begin{array}{l}\text { Mean } \\
\pm \text { SD }\end{array}$ \\
\hline No events & $\begin{array}{l}0.3 \pm \\
0.4\end{array}$ & $\begin{array}{l}0.4 \pm \\
0.4\end{array}$ & $\begin{array}{l}0.2 \pm \\
0.3\end{array}$ & $\begin{array}{l}0.5 \pm \\
0.7\end{array}$ & $\begin{array}{l}0.8 \pm \\
0.8\end{array}$ & $\begin{array}{l}0.3 \pm \\
0.7\end{array}$ & $\begin{array}{l}1.5 \pm \\
2.1\end{array}$ & $\begin{array}{l}2.5 \pm \\
2.2\end{array}$ & $\begin{array}{l}0.9 \pm \\
2.0\end{array}$ & $\begin{array}{l}52.4 \\
\pm 14.6\end{array}$ & $\begin{array}{l}62.2 \pm \\
8.6\end{array}$ & $\begin{array}{l}46.5 \pm \\
14.5\end{array}$ \\
\hline Chest pain & $\begin{array}{l}0.9 \pm \\
0.8\end{array}$ & $\begin{array}{l}1.3 \pm \\
0.7\end{array}$ & $\begin{array}{l}0.2 \pm \\
0.4\end{array}$ & $\begin{array}{l}1.3 \pm \\
1.1\end{array}$ & $\begin{array}{l}1.7 \pm \\
0.9\end{array}$ & $\begin{array}{l}0.3 \pm \\
0.7\end{array}$ & $\begin{array}{l}5.4 \pm \\
4.7\end{array}$ & $\begin{array}{l}7.4 \pm \\
4.2\end{array}$ & $\begin{array}{l}1.0 \pm \\
2.1\end{array}$ & $\begin{array}{l}59 \pm \\
10.5\end{array}$ & $\begin{array}{l}61.8 \pm \\
8.1\end{array}$ & $\begin{array}{l}53.0 \pm \\
13\end{array}$ \\
\hline HF & $\begin{array}{l}1.4 \pm \\
1.9\end{array}$ & $\begin{array}{l}2.0 \pm \\
1.8\end{array}$ & $\begin{array}{l}0.8 \pm \\
1.8\end{array}$ & $\begin{array}{l}2.1 \pm \\
2.2\end{array}$ & $\begin{array}{l}2.6 \pm \\
1.7\end{array}$ & $\begin{array}{l}1.6 \pm \\
2.7\end{array}$ & $\begin{array}{l}8.4 \pm \\
11.0\end{array}$ & $\begin{array}{l}11.8 \\
\pm 10.6\end{array}$ & $\begin{array}{l}4.8 \pm \\
10.7\end{array}$ & $\begin{array}{l}46.1 \\
\pm 13.1\end{array}$ & $\begin{array}{l}51.3 \pm \\
13\end{array}$ & $\begin{array}{l}40.5 \pm \\
11\end{array}$ \\
\hline Hospitalization & $\begin{array}{l}4.1 \pm \\
3.0\end{array}$ & $\begin{array}{l}4.7 \pm \\
2.9\end{array}$ & $\begin{array}{l}2.8 \pm \\
3\end{array}$ & $\begin{array}{l}5.5 \pm \\
3.5\end{array}$ & $\begin{array}{l}5.9 \pm \\
2.7\end{array}$ & $\begin{array}{l}4.8 \pm \\
4.7\end{array}$ & $\begin{array}{l}23.9 \\
\pm 17.8\end{array}$ & $\begin{array}{l}27.9 \\
\pm 16.9\end{array}$ & $\begin{array}{l}16.6 \\
\pm 17.7\end{array}$ & $\begin{array}{l}44.4 \\
\pm 14.9\end{array}$ & $\begin{array}{l}41.8 \pm \\
12.9\end{array}$ & $\begin{array}{l}49.1 \pm \\
17.3\end{array}$ \\
\hline Syncope & $\begin{array}{l}1.4 \pm \\
1.2\end{array}$ & $\begin{array}{l}1.9 \pm \\
1.1\end{array}$ & $\begin{array}{l}1.0 \pm \\
1.2\end{array}$ & $\begin{array}{l}2.5 \pm \\
1.9\end{array}$ & $\begin{array}{l}3.1 \pm \\
1.10\end{array}$ & $\begin{array}{l}2.1 \pm \\
1.9\end{array}$ & $\begin{array}{l}8.2 \pm \\
7.2\end{array}$ & $\begin{array}{l}11.3 \\
\pm 6.6\end{array}$ & $\begin{array}{l}5.9 \pm \\
7.2\end{array}$ & $\begin{array}{l}51.6 \\
\pm 19.3\end{array}$ & $\begin{array}{l}54.8 \pm \\
15.8\end{array}$ & $\begin{array}{l}49.3 \pm \\
22.3\end{array}$ \\
\hline VT & $\begin{array}{l}1.7 \pm \\
1.3\end{array}$ & $\begin{array}{l}1.6 \pm \\
1.2\end{array}$ & $\begin{array}{l}1.8 \pm \\
1.5\end{array}$ & $\begin{array}{l}2.4 \pm \\
1.7\end{array}$ & $\begin{array}{l}2.2 \pm \\
1.3\end{array}$ & $\begin{array}{l}2.6 \pm \\
2.2\end{array}$ & $\begin{array}{l}9.8 \pm \\
7.5\end{array}$ & $\begin{array}{l}9.4 \pm \\
7.3\end{array}$ & $\begin{array}{l}10.3 \\
\pm 8.8\end{array}$ & $\begin{array}{l}49.7 \\
\pm 16.2\end{array}$ & $\begin{array}{l}53.6 \pm \\
10.5\end{array}$ & $\begin{array}{l}44.8 \pm \\
22.3\end{array}$ \\
\hline Arrest & $\begin{array}{l}2.7 \pm \\
1.8\end{array}$ & $\begin{array}{l}3.3 \pm \\
1.8\end{array}$ & $\begin{array}{l}1.9 \pm \\
1.8\end{array}$ & $\begin{array}{l}3.3 \pm \\
1.7\end{array}$ & $\begin{array}{l}3.8 \pm \\
1.5\end{array}$ & $\begin{array}{l}2.5 \pm \\
1.9\end{array}$ & $\begin{array}{l}15.9 \\
\pm 10.8\end{array}$ & $\begin{array}{l}19.1 \\
\pm 10.8\end{array}$ & $\begin{array}{l}11.0 \\
\pm 10.3\end{array}$ & $\begin{array}{l}60.9 \\
\pm 10.5\end{array}$ & $\begin{array}{l}58.7 \pm \\
13.3\end{array}$ & $\begin{array}{l}64.3 \pm \\
4.0\end{array}$ \\
\hline
\end{tabular}

\section{Discussion}

Although each of the three methods used to quantify the myocardial scar using LGE in CMR has a different concept to calculate the size of the scar, they all showed comparable results.

The manual method is known to be the most accurate, however, extremely time consuming. In addition, we face some technical problems when there are two or more non-connected scar mass in the same short axis slice. The second method using the total number of segments involving any late gadolinium enhancement is theoretically less accurate as it consider one segment affected even the late 
enhancement is focal or minimal. On the other hand it is the least time consuming method by only giving a general impression about how many of the myocardial segments include a scarred tissue.

However, the 3rd method by summation of the amount of each segment with scarred myocardium (\% of each segment with a scar), is less time consuming than the manual one with considerable accuracy representing how much of the myocardium is unhealthy.

Many other methods were tested and compared for the accuracy to quantify the myocardial scar; e.g. Flett et al.[4] studied the reproducibility of LGE quantification techniques in 3 different pathological conditions; acute myocardial infarction (AMI), chronic myocardial infarction (CMI) and hypertrophic cardiomyopathy ( $\mathrm{HCM})$, using 7 techniques; including manual quantification, automatic methods including; thresholding by $2,3,4,5$, or 6 SDs above remote myocardium, and the full width at half maximum (FWHM) technique. They concluded that regardless of the underlying disease, the FWHM technique for LGE quantification gives LGE volume mean results similar to manual quantification and is statistically the most reproducible, reducing required sample sizes by up to onehalf.[4]

Another study by Gao et al.[5] using automatic thresholding; measured a 50\% larger scar size going from 5-SD to 2-SD thresholds above remote myocardial signal intensity. Neilan et al.[6] found that scar size was, on average, $50 \%$ greater using the 2-SD technique versus the FWHM technique ( $9 \pm 5 \%$ by 2 -SD method vs. $6 \pm 4 \%$ by FWHM method); however, there was close correlation between both the measurements $(r=0.92, p<0.001)$, and more importantly, both methods of quantification showed robust prognostic association.

This means; despite the different ways used to quantify the myocardial scar, the manual assessment is considered one of the most accurate methods, however, no one specific method agreed to be the standard yet.

In our study, we are mainly concerned about the prognostic value of the scar value and if there is a linked to the clinical outcome of cardiomyopathy. It was clearly observed that there is a clear linear relationship between the size of the myocardial scar (using any of the 3 methods) and the severity of the clinical events. More serious cardiac events eg; hospitalization, serious arrhythmias and sudden cardiac arrest were more detected in patients with larger scar size in both groups ( $\mathrm{P}$ value $<0.001),(\mathrm{Fig} .4,5,6)$.

In our study, we were not just interested in the sudden cardiac arrest as the main outcome, however, the wider spectrum of the clinical events is thought to give more data about the expected clinical pattern, hence, the treatment plan and cardiac patient expected quality of life.

It was observed that serious cardiac events were less seen in patient with mean scar mass $<5.4-8.4 \%$. On the contrary, patients who have experienced sudden cardiac arrest have a mean scar mass of $15.9 \%$ and patients with ventricular tachycardia with mean of $9.8 \%$ (Table 1). It was also interesting that the hospitalization with heart failure manifestations is significantly more frequent with high scar mass specially in ischaemic patients with mean of $27.9 \%$. This may be explained as the scar amount in ischaemic cardiomyopathy is directly reflecting the severity of the baseline coronary artery disease and number of territories involved. Another finding that may support this theory is the mean EF for those patients was $<45 \%$.

Many of the other studies were focused mainly on the link of the myocardial scar and sudden cardiac death to guide the indication for ICD implantation, giving less attention to the rest of the clinical spectrum of the outcome. For example, Neilan et al.[6] demonstrated that for every $1 \%$ of LV mass increase in scar size, the risk of cardiovascular death or ventricular arrhythmia increases by $15 \%$. This relationship was similar whether scar size was measured using the 2-SD method (HR, 1.15; 95\% confidence interval, 1.12-1.18) or the FWHM-method (HR, 1.16; 95\% confidence interval, 1.12-1.20). When only arrhythmic events were considered, the extent of scar was again associated with higher event risk (HR, 1.17 for each $1 \%$ absolute increase in scar size; $95 \%$ confidence interval, 1.12-1.22). Similar results were reported by Gulati et al.[7] for each percent scar extent the risk of all-cause mortality was increased by $11 \%$ (HR, $1.11 ; 95 \%$ confidence interval, 1.06-1.16), and the risk for arrhythmic events was increased by $10 \%$ (HR, 1.10; $95 \%$ confidence interval, $1.05-1.16)$.

Li et al.[8] aimed to develop a risk score (LGE Based Prediction of SCD Risk in Non-ischemic Dilated Cardiomyopathy [ESTIMATED]) based on late gadolinium enhancement (LGE) in CMR to predict sudden cardiac death (SCD) in patients with non-ischemic dilated cardiomyopathy (NIDCM) and left ventricular EF $\leq 35 \%$. They followed up 395 patients with NIDCM for 3 years for SCD events. The ESTIMATED score (constructed by the LGE extent > 14\%, syncope, atrial flutter/fibrillation, non-sustained ventricular tachycardia, advanced atrioventricular block, and age $\leq 20$ or $>50$ years) showed good calibrations for SCD prediction.[8] By the score, $20.3 \%$ of primary prevention patients were categorized as high risk ( $\geq 3$ points), $28.1 \%$ as intermediate risk ( 2 points), and $51.6 \%$ as low risk ( $0-1$ 
points) for 3-year SCD events ( $45.9 \%$ vs $20.1 \%$ vs $5.1 \%, P<0.0001$ ). The 3-year SCD events were also well in agreement with the score stratification in patients without implantable cardioverter-defibrillator.[8]

Their study suggested LGE-based (ESTIMATED) risk score to be validated in providing refined SCD prediction. The score may help to identify candidates for primary prevention implantable cardioverter-defibrillator in patients with NIDCM.[8]

However, our study included both ischaemic and non-ischaemic spectrum, studied them independently and also compared to each other. Moreover, the follow up included a wide spectrum of clinical events ranging from mild chest pain or shortness of breath, passing through hospitalization due to decompensated heart failure and up to malignant arrhythmia and sudden cardiac arrest. We were more concerned about the clinical pattern of the patients regarding their morbidity, hospitalization and quality of life.

The mean EF was $51 \%+/-14(18-77 \%)$ in group I (32\% of group I with $\mathrm{EF}<45 \%$ and $69 \%$ with $\mathrm{EF}>45 \%)$ and $48 \%+/-16(9-77 \%)$ in group II ( $37 \%$ of group I with $\mathrm{EF}<45 \%$ and $63 \%$ with $\mathrm{EF}>45 \%)$.

There was a statistically significant linear relationship between the LV systolic dysfunction represented by LVEF and event severity in group I (ischaemic) with $\mathrm{P}$ value of 0.013 . On the opposite for the non-ischaemic cardiomyopathy, there was no clear relationship between the LVEF and event severity (P value 0.150 ). In this group (non-ischaemic), the main predictor of cardiac events was the scar mass. For example; the four patients in group II that experienced sudden cardiac arrest the EF was above $45 \%$ but with high scar mass average (13.99 gm \pm 13.77$)$.

It was also observed in group I (ischaemic), the lower EF was more linked with hospitalization due to decompensated heart failure (63\% of the hospital admissions has EF $<45 \%$ ). In contrary, most of the patients with no events or mild chest pain or dyspnoea have $E F>45 \%$. This could be explained as in ischaemic patients the amount of the scarred myocardium is directly linked to the severity of the underlying coronary artery disease and the amount of scar mass and its distribution may also indicated the number of coronary territory affected.

In the non-ischaemic patients, usually the preserved LVEF is usually misleading because it is not indicating the degree of the underlying myocardial pathology. However, LGE in cardiac MRI is more precise in tissue characterization and spotting the unhealthy myocardium that is usually a substrate for serious arrhythmogenic events and subsequently sudden cardiac arrest even in cases of preserved EF.

In Dokainish et al.[9] they had similar outcome to ours when they evaluated the prognostic implications of left ventricle (LV) systolic and diastolic dysfunction early post-acute ST-segment elevation myocardial infarction (STEMI). Patients with LV ejection fraction (LVEF) $\leq$ $45 \%$ and restrictive diastolic function (RDF) were at greatly increased risk of MACE (hazard ratio $[\mathrm{HR}]=8.85,95 \% \mathrm{Cl}, 4.21-18.60$ ) compared to patients with LVEF $\geq 45 \%$ and without RDF. RDF remained a strong predictor for MACE in patients with LVEF $\geq 45 \%$ (HR $=$ $4.38,95 \% \mathrm{Cl}, 1.52-12.60$ ) and in multivariate models adjusted for LVEF, LV end-systolic volume, and clinical variables.

Regarding non-ischaemic cardiomyopathy, Ge et al.[10] investigated if structural abnormality on cardiac magnetic resonance imaging (CMR) represented by LGE may be a predictor of major adverse cardiac events (MACE) in patients with non-sustained ventricular tachycardia (NSVT) and ventricular tachycardia (VT)/sudden cardiac death (SCD).

They studied 651 patients (ages, $54 \pm 15 ; 61 \%$ men) referred to CMR for ventricular arrhythmia were divided into 2 groups, according to the presence of NSVT (53\%) or sustained VT/aborted SCD (47\%). MACE was a composite of cardiovascular death, a need for heart transplantation or left ventricular assist device, and recurrent VT/ventricular fibrillation needing therapy. The mean left ventricular ejection fraction was $54 \pm 13 \%$, and late gadolinium enhancement (LGE) was present in $39 \%$ of patients (mean, $9.5 \pm 8 \%$ ). [10]

A structurally abnormal heart, defined by LGE, abnormalities in wall motion, or impaired systolic function, was observed in $52 \%$ of patients $(n=336)$. A change in diagnostic impression based on CMR took place for $27 \%$ of patients with NSVT vs $40 \%$ of patients with VT/SCD $(P<.001)$. A total of 122 patients experienced a MACE during the follow-up period (median, 3.6 years). Structural abnormality detected on CMR was found to be an independent predictor of MACE (hazard ratio, 3.65; 95\% Cl, 2.09-6.27; $P<.001$ ). [10]

The small number of patients included in our study, especially in each type of non-ischaemic cardiomyopathy is one of the limitations for our study. In addition, longer follow up duration would have added more significant predictive value.

\section{Conclusion}


- Myocardial scar/fibrosis using cardiac magnetic resonance is a reliable parameter that can reflect the degree of diseased myocardium. The amount of scarred or fibrosed myocardium is found to be directly linked to the severity of the clinical event in both ischaemic and non-ischaemic cardiomyopathy. The larger the scar size, the more severe is the clinical event, even with preserved ventricular ejection fraction. Therefore, quantification of myocardial scar/fibrosis could be used as a predictor for cardiac events, hospitalization and sudden cardiac death.

- Ejection fraction is not always linked with the severity of cardiac event, especially in non-ischaemic cardiomyopathy. Low ejection fraction was mainly linked with hospitalization in both ischaemic and non-ischaemic cardiomyopathy.

- Several methods are used to quantify the size of myocardial scar/fibrosis. Manual technique is considered one of the most accurate methods, however, it is extremely time consuming. Less time consuming alternative techniques are yet to be approved.

\section{Declarations}

\section{Compliance with Ethical Standards}

Conflict of Interest: The authors declare that they have no conflict of interest.

Informed Consent: Informed consent was obtained from all individual participants included in the study.

Human and Animal Rights: All procedures performed in studies involving human participants were in accordance with the ethical standards of the institutional and/or national research committee and with the 1964 Helsinki Declaration and its later amendments or comparable ethical standards. The study protocol got the approval of the Committee of Ethics, Faculty of Medicine, Alexandria University.

Availability of data and material: Materials and data of the research are available upon request.

Funding: This research did not receive any specific grant from funding agencies in the public, commercial, or not-for-profit sectors.

Authors' Contribution: All authors declare that they have substantially contributed to the manuscript and have met the main criteria of author-ship: conceptualization, methodology, data collecting and processing, writing and editing, and supervision. All the authors agreed to publish the paper.

\section{References}

1. Klein C, Schmal TR, Nekolla SG, Schnackenburg B, Fleck E, Nagel E (2007) Mechanism of late gadolinium enhancement in patients with acute myocardial infarction. J Cardiovasc Magn Reson 9(4):653-658. https://doi.org/:10.1080/10976640601105614

2. Kelle S, Roes SD, Klein C, Kokocinski T, de Roos A, Fleck E, Bax JJ, Nagel E (2009) Prognostic value of myocardial infarct size and contractile reserve using magnetic resonance imaging. J Am Coll Cardiol 54(19):1770-1777.

https://doi.org/:10.1016/j.jacc.2009.07.027

3. Kim RJ, Fieno DS, Parrish TB, Harris K, Chen EL, Simonetti O, Bundy J, Finn JP, Klocke FJ, Judd RM (1999) Relationship of MRI delayed contrast enhancement to irreversible injury, infarct age, and contractile function. Circulation 100(19):1992-2002. https://doi.org/:10.1161/01.cir.100.19.1992

4. Flett AS, Hasleton J, Cook C, Hausenloy D, Quarta G, Ariti C, Muthurangu V, Moon JC (2011) Evaluation of techniques for the quantification of myocardial scar of differing etiology using cardiac magnetic resonance. JACC Cardiovasc Imaging 4(2):150-156. https://doi.org/:10.1016/j.jcmg.2010.11.015

5. Gao P, Yee R, Gula L, Krahn AD, Skanes A, Leong-Sit P, Klein GJ, Stirrat J, Fine N, Pallaveshi L, Wisenberg G, Thompson TR, Prato F, Drangova M, White JA (2012) Prediction of arrhythmic events in ischemic and dilated cardiomyopathy patients referred for implantable cardiac defibrillator: evaluation of multiple scar quantification measures for late gadolinium enhancement magnetic resonance imaging. Circ Cardiovasc Imaging 5(4):448-456. https://doi.org/:10.1161/circimaging.111.971549

6. Neilan TG, Coelho-Filho OR, Danik SB, Shah RV, Dodson JA, Verdini DJ, Tokuda M, Daly CA, Tedrow UB, Stevenson WG, JeroschHerold M, Ghoshhajra BB, Kwong RY (2013) CMR quantification of myocardial scar provides additive prognostic information in nonischemic cardiomyopathy. JACC Cardiovasc Imaging 6(9):944-954. https://doi.org/:10.1016/j.jcmg.2013.05.013

7. Gulati A, Jabbour A, Ismail TF, Guha K, Khwaja J, Raza S, Morarji K, Brown TD, Ismail NA, Dweck MR, Di Pietro E, Roughton M, Wage R, Daryani Y, O'Hanlon R, Sheppard MN, Alpendurada F, Lyon AR, Cook SA, Cowie MR, Assomull RG, Pennell DJ, Prasad SK (2013) 
Association of fibrosis with mortality and sudden cardiac death in patients with nonischemic dilated cardiomyopathy. JAMA 309(9):896-908. https://doi.org/:10.1001/jama.2013.1363

8. Li X, Fan X, Li S, Sun W, Shivkumar K, Zhao S, Lu M, Yao Y (2020) A Novel Risk Stratification Score for Sudden Cardiac Death Prediction in Middle-Aged, Nonischemic Dilated Cardiomyopathy Patients: The ESTIMATED Score. Can J Cardiol 36(7):1121-1129. https://doi.org/:10.1016/j.cjca.2019.11.009

9. Dokainish H, Rajaram M, Prabhakaran D, Afzal R, Orlandini A, Staszewsky L, Franzosi MG, Llanos J, Martinoli E, Roy A, Yusuf S, Mehta S, Lonn E (2014) Incremental value of left ventricular systolic and diastolic function to determine outcome in patients with acute ST-segment elevation myocardial infarction: the echocardiographic substudy of the OASIS-6 trial. Echocardiography 31(5):569-578. https://doi.org/:10.1111/echo.12452

10. Ge Y, Antiochos P, Qamar I, Seno A, Steigner ML, Aghayev A, Blankstein R, Stevenson W, Jerosch-Herold M, Kwong RY (2020) Diagnostic impact and prognostic value of cardiac mri in patients with ventricular arrhythmias. J Am Coll Cardiol 75(11 Supplement 1):3665

\section{Figures}
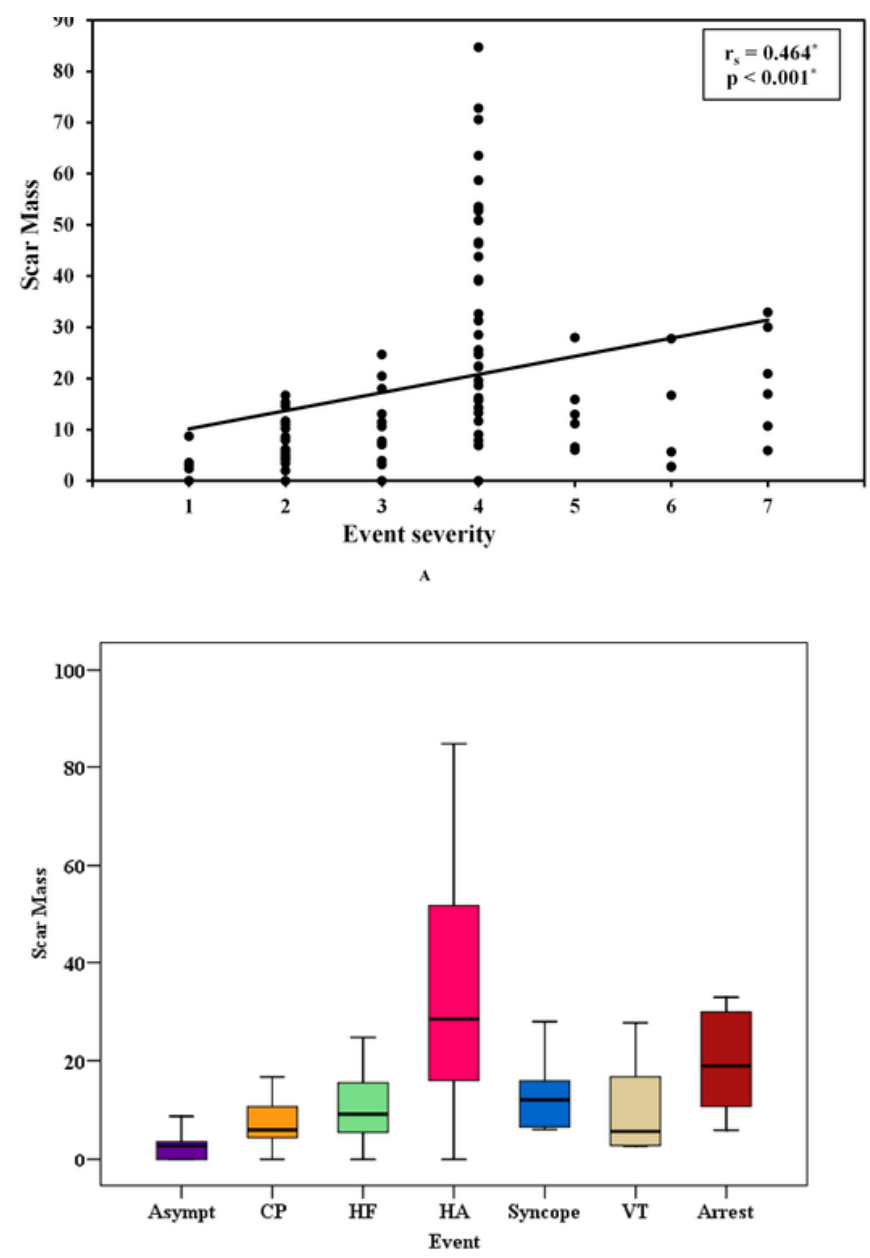

c
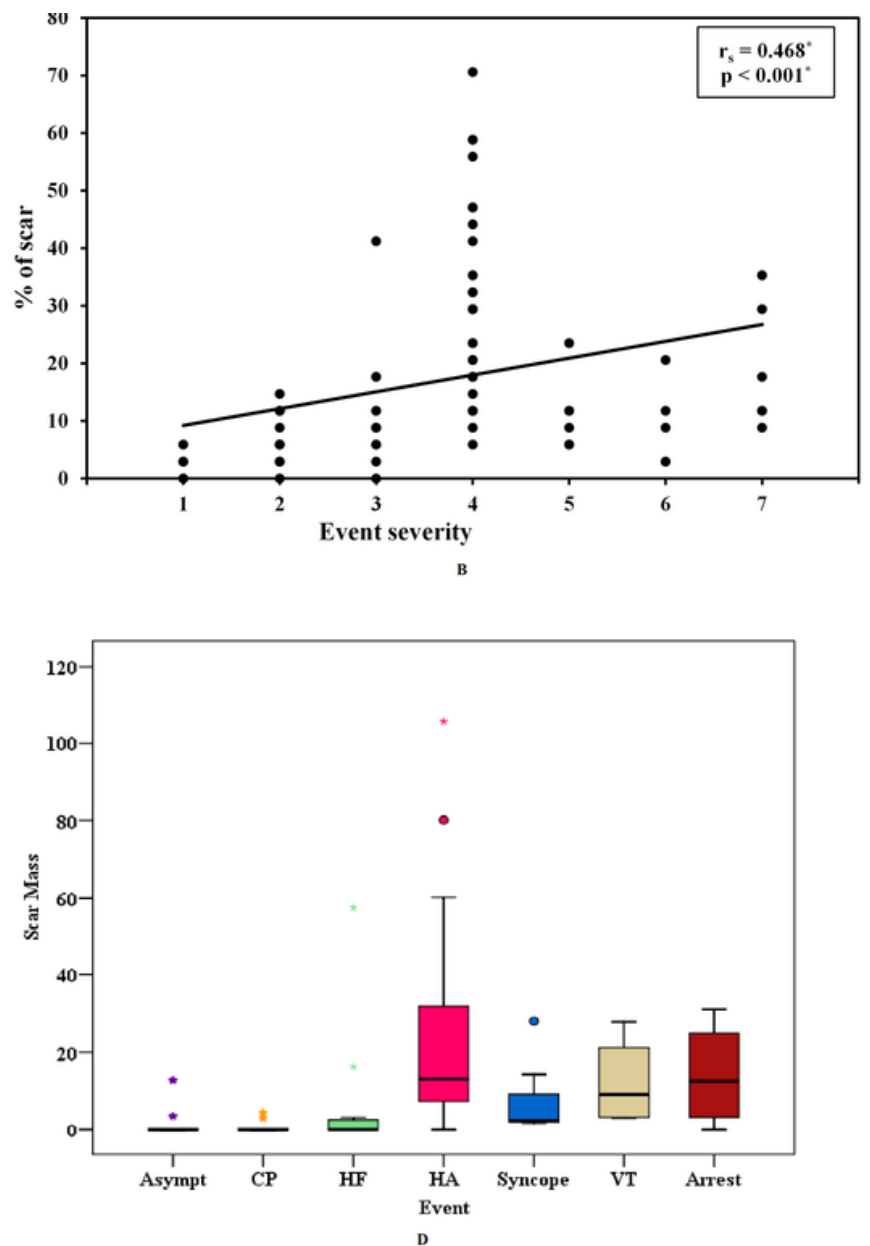

\section{Figure 1}

Relation between event severity and scar mass; A) and C) for Group I, B) and D) for Group II 

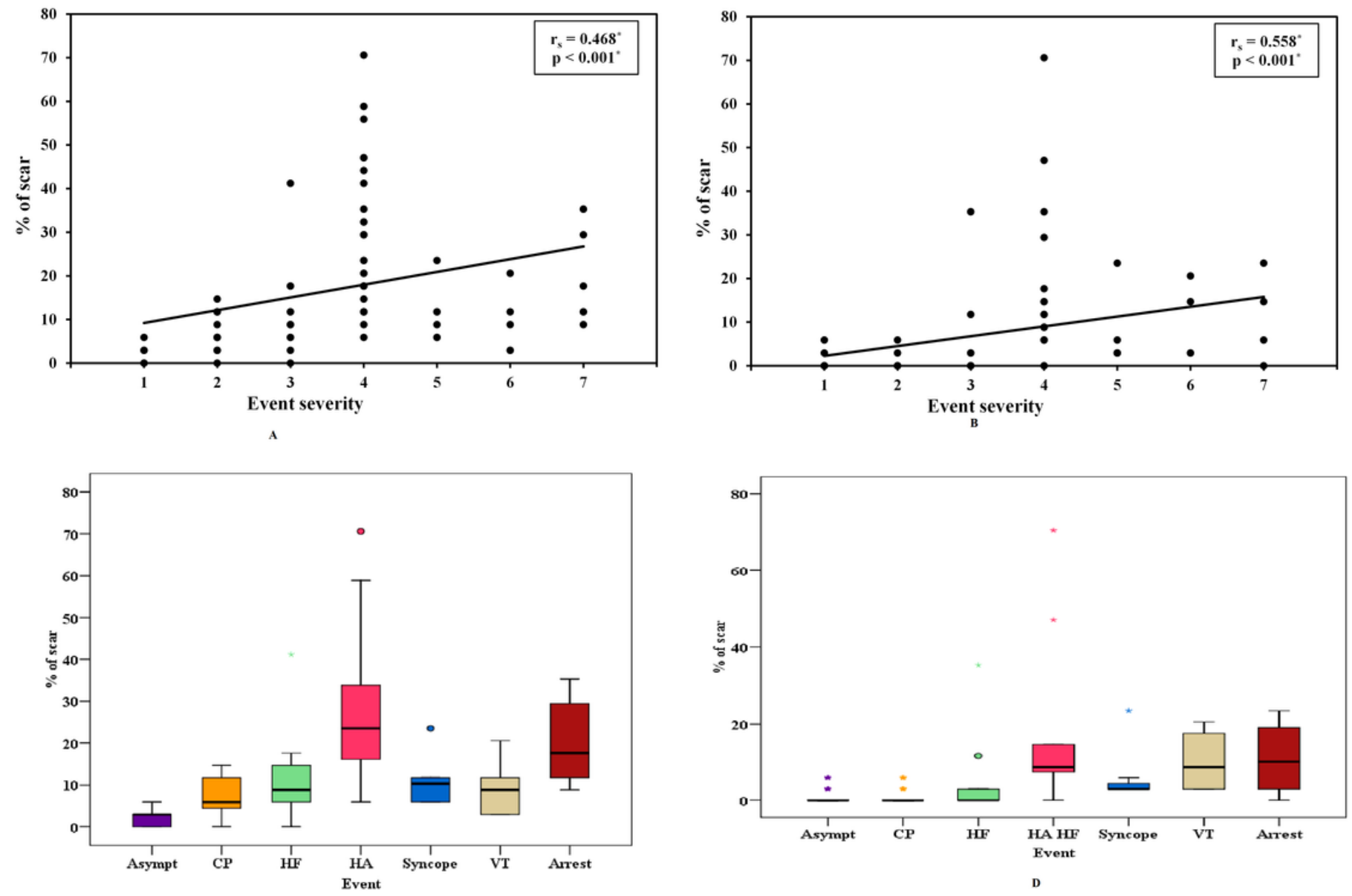

Figure 2

Relation between event severity and scar percentage ; A) and C) for Group I, B) and D) for Group II 

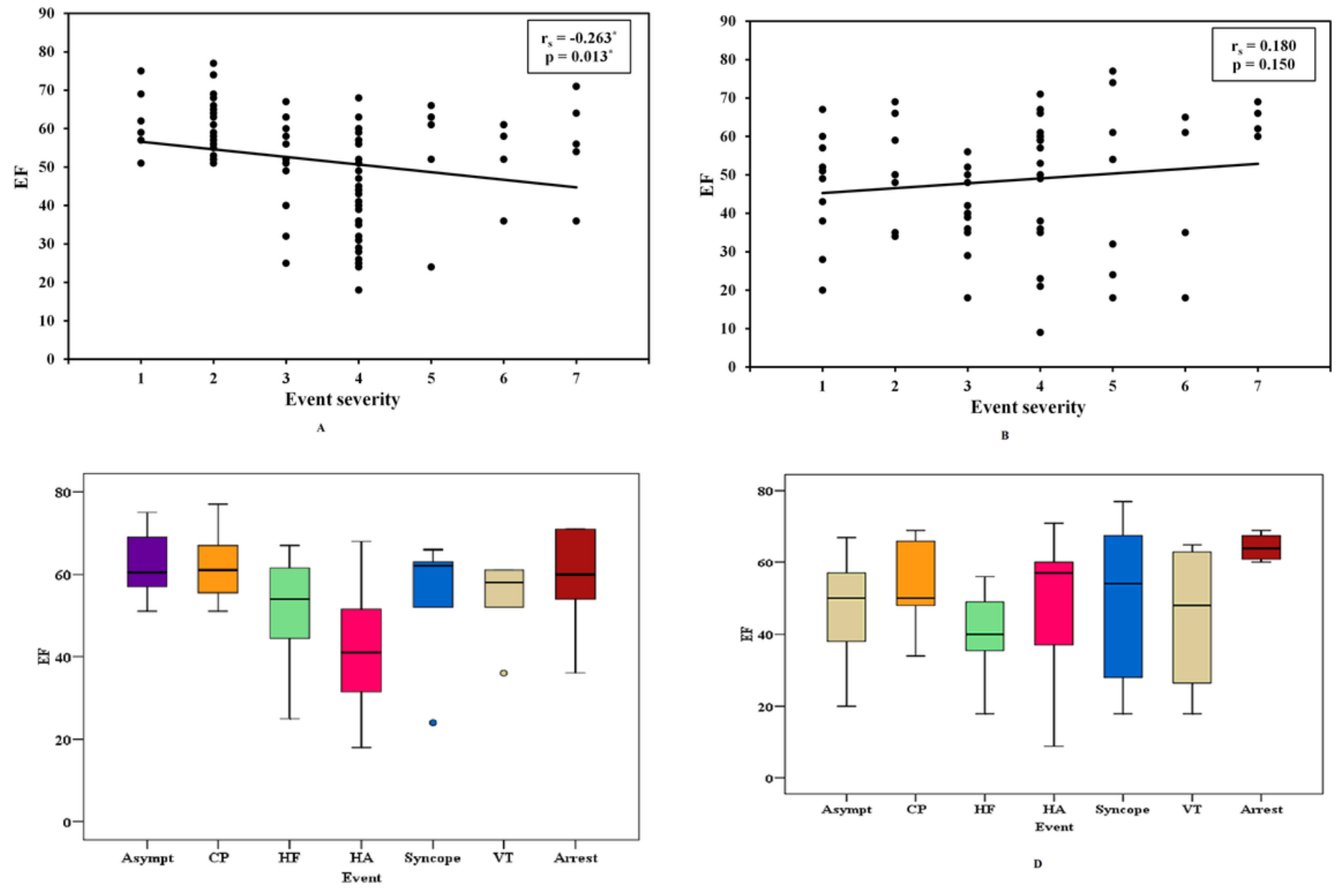

Figure 3

Relation between event severity and EF; A) and C) for Group I, B) and D) for Group II 


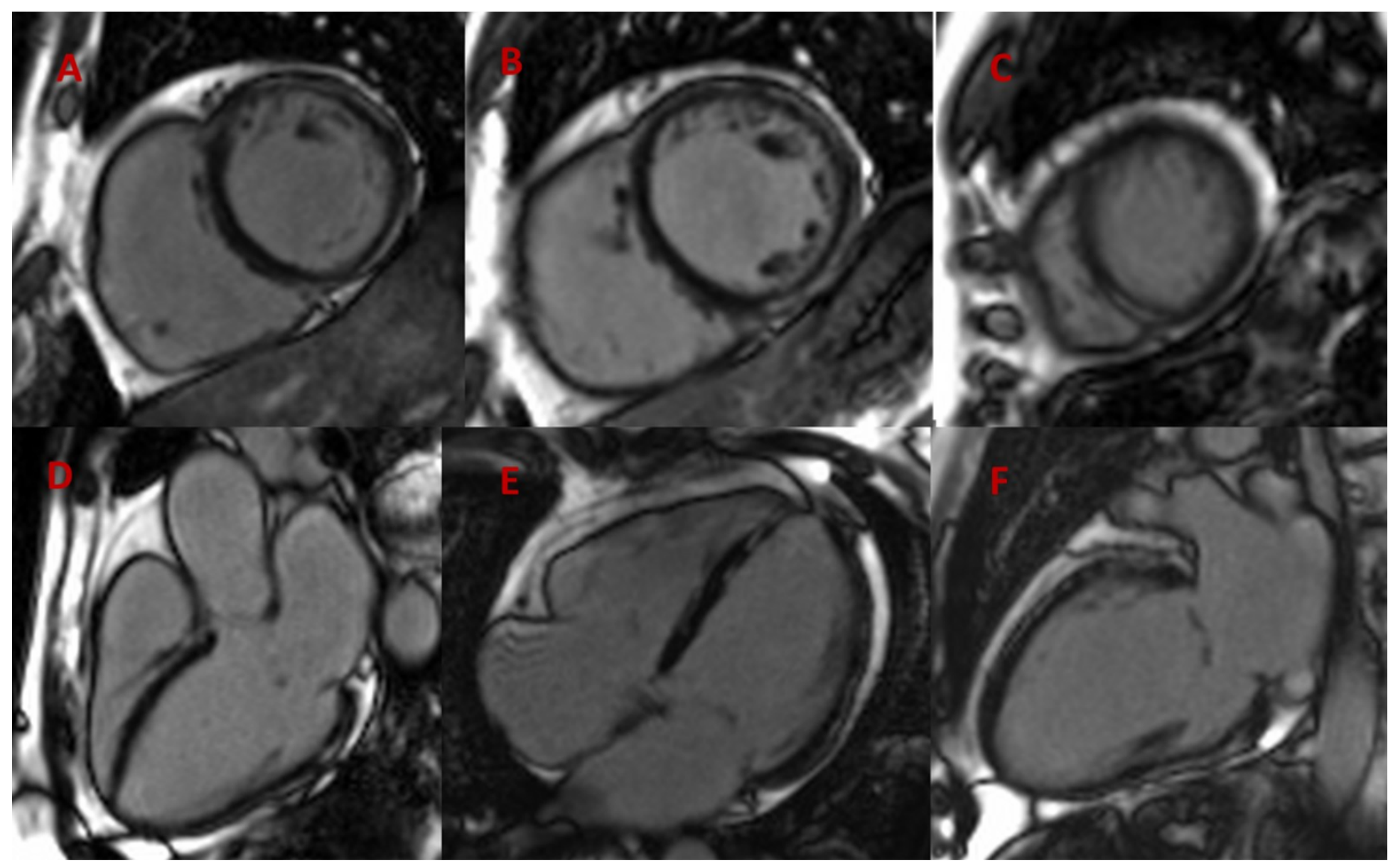

Figure 4

CMR LGE images ; A) basal, B) mid-cavity, C) apical SA, D) 3C, E) 4C and F) 2C long axis showing extensive mid-myocardial fibrosis for a patient with arrhythmogenic LV cardiomyopathy, with family history of SCD, repeated syncopal episodes, holter showed frequent multifocal ventricular ectopic beats, LVEF 56\%, scar mass of $9.9 \mathrm{gm}, 16 \%$ of myocardial mass, detected in 8 segments. 


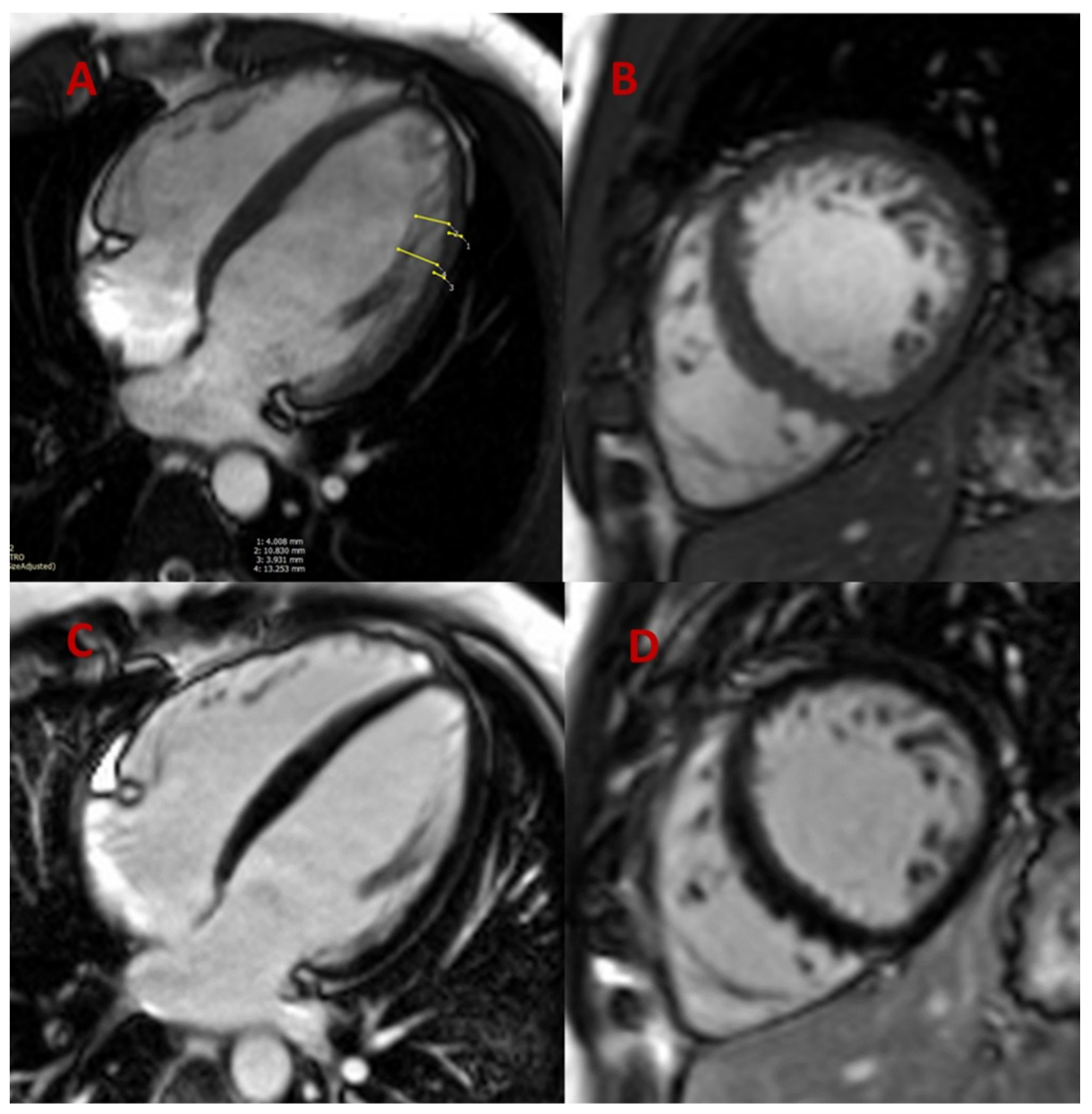

\section{Figure 5}

CMR images A) and B) 4C and SA Cine images, C) and D) 4C and SA LGE of LV non-compaction, asymptomatic patient (9m of FU) with no myocardial scar/fibrosis, EF $47 \%$. 




\section{Figure 6}

CMR images A) and B) SA and 2 C cine images, C) and D) SA and 2C LGE images showing transmural myocardial scar of the basal and mid-cavity inferior and inferolateral segments (4 segments), partially involving both papillary muscles, evaluated myocardial scar mass of $28 \mathrm{~g}$, representing $24 \%$ of the myocardium. 